\title{
Mice with GNAO1 R209H Movement Disorder Variant Display Hyperlocomotion Alleviated by Risperidone ${ }^{[\mathrm{S}}$
}

\author{
Casandra L. Larrivee, Huijie Feng, Josiah A. Quinn, Vincent S. Shaw, Jeffrey R. Leipprandt, \\ Elena Y. Demireva, Huirong Xie, and $\odot$ Richard R. Neubig \\ Department of Comparative Medicine and Integrative Biology (C.L.L.), Department of Pharmacology and Toxicology \\ (C.L.L., H.F., J.A.Q., V.S.S., J.R.L., R.R.N.), Transgenic and Genome Editing Facility, Institute for Quantitative Health Science \\ and Engineering (E.Y.D., H.X.), and Nicholas V. Perricone, M.D., Division of Dermatology, Department of Medicine (R.R.N.), \\ Michigan State University, East Lansing, Michigan
}

Received September 28, 2019; accepted December 27, 2019

\begin{abstract}
Neurodevelopmental disorder with involuntary movements (Online Mendelian Inheritance in Man: 617493) is a severe, early onset neurologic condition characterized by a delay in psychomotor development, hypotonia, and hyperkinetic involuntary movements. Heterozygous de novo mutations in the GNAO1 gene cause neurodevelopmental disorder with involuntary movements. $\mathrm{G} \alpha_{\mathrm{o}}$, the gene product of GNAO1, is the alpha subunit of $G_{0}$, a member of the heterotrimeric $G_{i / o}$ family of $G$ proteins. $G_{o}$ is found abundantly throughout the brain, but the pathophysiological mechanisms linking $\mathrm{G} \alpha$ o functions to clinical manifestations of GNAO1-related disorders are still poorly understood. One of the most common mutant alleles among the GNAO1 encephalopathies is the c.626G $>$ A or p.Arg209His $(\mathrm{R} 209 \mathrm{H})$ mutation. We developed heterozygous knock-in Gnao1 ${ }^{+/ R 209 H}$ mutant mice using CRISPR/Cas9 methodology to assess whether a mouse model could replicate aspects of the neurodevelopmental disorder with involuntary movements clinical pattern. Mice carrying the R209H mutation exhibited increased locomotor activity and a modest gait abnormality at 8-12 weeks. In contrast to mice carrying other mutations in Gnao1, the Gnao1 $1^{+/ R 209 H}$ mice did not show
\end{abstract}

\section{Introduction}

$\mathrm{G} \alpha_{\mathrm{o}}$ is the alpha subunit of the heterotrimeric $\mathrm{G}$ protein $\mathrm{G}_{\mathrm{o}}$. It is the most abundant heterotrimeric $G$ protein in the central nervous system, comprising $1 \%$ of mammalian brain membrane protein. Mutations in GNAO1, which encodes $\mathrm{G} \alpha_{0}$, have been linked to two distinct neurologic conditions. In 2013, four children with early infantile epileptic encephalopathy were identified with mutations in GNAO1 (Nakamura et al., 2013). Since then, a growing number of patients presenting with epilepsy and/or hyperkinetic movement disorders have been found to exhibit de novo mutations in GNAO1 (Feng et al.,

This work was supported by a grant from the Bow Foundation [2], Michigan State University's (MSU's) department of Comparative Medicine and Integrative Biology, and the MSU discretionary funding initiative [34149].

https://doi.org/10.1124/jpet.119.262733.

S This article has supplemental material available at jpet.aspetjournals.org. enhanced seizure susceptibility. Levels of protein expression in multiple brain regions were unchanged from wild-type (WT) mice, but the nucleotide exchange rate of mutant R209H G $\alpha_{\text {o }}$ was $6.2 \times$ faster than WT. The atypical neuroleptic risperidone has shown efficacy in a patient with the $\mathrm{R} 209 \mathrm{H}$ mutation. It also alleviated the hyperlocomotion phenotype observed in our mouse model but suppressed locomotion in WT mice as well. In this study, we show that Gnao $1^{+/ R 2 O O H}$ mice mirror elements of the patient phenotype and respond to an approved pharmacological agent.

\section{SIGNIFICANCE STATEMENT}

Children with de novo mutations in the GNAO1 gene may present with movement disorders with limited effective therapeutic options. The most common mutant variant seen in children with GNAO1-associated movement disorder is $\mathrm{R} 209 \mathrm{H}$. Here we show, using a novel Gnao $1^{+/ R 209 H}$ mouse, that there is a clear behavioral phenotype that is suppressed by risperidone. However, risperidone also affects wild-type mouse activity, so its effects are not selective for the GNAO1associated movement disorder.

ABBREVIATIONS: BODIPY, boron-dipyrromethene; GOF, gain-of-function; gRNA, guide RNA; HEK, human embryonic kidney; PCR, polymerase chain reaction; PTZ, pentylenetrazol; RIPA, radioimmunoprecipitation assay; ssODN, single-stranded oligodeoxynucleotide; WT, wild type. 
Waak et al., 2018; Xiong et al., 2018; Kelly et al., 2019; Schirinzi et al., 2019).

More than 40 pathologic variants of GNAO1 have been reported. Using a cell-based biochemical signaling assay, we classified many of those $\mathrm{G} \alpha_{\mathrm{o}}$ variants for their ability to inhibit cAMP production in transfected human embryonic kidney (HEK) 293 cells (Feng et al., 2017). Some mutant $\mathrm{G} \alpha_{\mathrm{o}}$ proteins were unable to support receptor-mediated inhibition of cAMP, which classifies them as having a loss-of-function mechanism in vitro. These loss-of-function mutants were associated with epilepsy (Feng et al., 2017). In contrast, mutations resulting in enhanced cAMP inhibition [gain-of-function (GOF)] or normal cAMP regulation were generally associated with movement disorders (Feng et al., 2017).

To permit mechanistic studies and preclinical drug testing, we had previously created a mouse model with a GNAO1 GOF mutation, G203R, that was identified in patients who showed both epilepsy and movement disorders (Saitsu et al., 2016). As predicted, the Gnao1 ${ }^{+/ \mathrm{G} 203 \mathrm{R}}$ (G203R) mutant mice exhibited motor coordination and gait abnormalities as well as enhanced seizure susceptibility in pentylenetrazol (PTZ) kindling studies (Feng et al., 2019). The R209H mutations are some of the most common pathogenic GNAO1 mutations (Schirinzi et al., 2019). Patients with de novo, heterozygous R209H mutations in GNAO1 display severe choreoathetosis and dystonia but do not exhibit seizures (Supplemental Table 1). Interestingly, the R209H mutation was found to have essentially normal function for cAMP inhibition in HEK293T cells. Despite this normal function in an in vitro assay, it causes a severe form of movement disorder in patients, often requiring intensive care unit admission (Ananth et al., 2016; Marecos et al., 2018). This discrepancy between the normal functionality in vitro and its clear clinical pathologic role makes the $\mathrm{R} 209 \mathrm{H}$ mutation of substantial interest for in vivo physiologic studies.

We used a battery of behavioral tests to measure motor skills in heterozygous Gnao1 $1^{+/ R 209 H}$ mutant mice as well as PTZ kindling studies to assess seizure susceptibility. As expected, Gnao1 $1^{+/ R 209 H}$ mice did not show enhanced seizure susceptibility in PTZ kindling studies. Male and female Gnao $1^{+/ R 209 H}$ mice displayed significant hyperactivity in an open field assessment. This finding was surprising because mice in our previous GNAO1-related movement disorder model, Gnao1 $1^{+/ G 203 R}$, did not show significant differences on the open field test (Feng et al., 2019). This difference in movement phenotype is consistent with the wide heterogeneity of movement patterns displayed by patients with GNAO1 mutations (Nakamura et al., 2013; Ananth et al., 2016; Dhamija et al., 2016; Kulkarni et al., 2016; Marcé-Grau et al., 2016; Menke et al., 2016; Feng et al., 2018).

Having a mouse model with a strong movement phenotype facilitates mechanistic studies of GNAO1 mutants, and this allowed us to begin allele-specific preclinical drug testing. The neuroleptic risperidone was reportedly beneficial in a patient with a GNAO1 R209H mutation (Ananth et al., 2016). Here we show risperidone attenuates hyperactivity in our R209H mutant mice. This suggests risperidone or related agents may be beneficial for GNAO1 patients with the R209H mutation.

\section{Materials and Methods}

Animals. Gnao $1^{+/ R 209 H}$ mice on a C57BL/6J background were generated in the Michigan State University Transgenic and Gene
Editing Facility (https://tgef.vprgs.msu.edu) as described below. Mice (8-12 weeks old) were housed on a 12-hour light/dark cycle with ad libitum access to food and water. All experiments were performed in accordance with National Institutes of Health guidelines, and protocols were approved by the Michigan State University Institutional Animal Care and Use Committee.

Generation of Gnao1 R209H Edited Mice. Mutant Gnao $1^{+/ R 209 H}$ mice were generated via CRISPR/Cas9 genome editing on a C57BL/6J genomic background. CRISPR guide RNA (gRNA) selection and locus analysis were performed using the Benchling platform (Benchling, Inc., San Francisco, CA). A gRNA targeting exon 6 of the Gnao1 locus (ENSMUSG00000031748) was chosen to cause a double-strand DNA break 3 bp downstream of codon R209. A single-stranded oligodeoxynucleotide (ssODN) carrying the R209H mutation CGC > CAC with short homology arms was used as a repair template (Fig. 1; Table 1). Ribonucleoprotein complexes consisting of a synthetic CRISPR RNA/trans-activating CRISPR RNA hybrid and Alt-R S.p. Cas9 Nuclease V3 protein (Integrated DNA Technologies, Inc., Coralville, IA) were used to deliver CRISPR components along with the ssODN to mouse zygotes via electroporation as previously described (Feng et al., 2017, 2019). Edited embryos were implanted into pseudo-pregnant dams using standard techniques. Resulting litters were screened by polymerase chain reaction (PCR) (Phire Green HSII PCR Mastermix, F126L; Thermo Fisher, Waltham, MA), T7 Endonuclease I assay (M0302; New England Biolabs Inc.), and Sanger sequencing (GENEWIZ, Inc., Plainfield, NJ) for edits of the target site.

Genotyping and Breeding. Studies were done on N1 R209H heterozygotes with comparisons to littermate controls. To generate Gnao $^{+/ R 209 H}$ heterozygotes (N1 backcross), two founder Gnao1 $1^{+/ R 209 H}$ mice, one male and one female, were crossed with wild-type (WT) C57BL/ $6 \mathrm{~J}$ mice obtained directly from The Jackson Laboratory (Bar Harbor, ME).

DNA was extracted by an alkaline method (Kehrl et al., 2014) from ear clips done before weaning. PCR products were generated with primers flanking the mutation site (Forward 5' GGACAGGTGTCACA GGGGAT 3'; 5' ACTGGCCTCCCTTGGCAATA 3'), which produces a 375 -bp product. Reaction conditions were: $0.8 \mu$ l template, $4 \mu \mathrm{l} 5 \times$ Promega PCR buffer, $0.4 \mu \mathrm{l} 10 \mathrm{mM}$ deoxyribonucleotide triphosphates, $1 \mu \mathrm{l} 10 \mu \mathrm{M}$ Forward Primer, $1 \mu \mathrm{l} 10 \mu \mathrm{M}$ Reverse Primer, $0.2 \mu \mathrm{l}$ Promega GoTaq, and 12.6 $\mu \mathrm{l}$ DNase free water (catalog no. M3005; Promega, Madison, WI). Samples were denatured for 4 minutes at $95^{\circ}$ $\mathrm{C}$ and then underwent 32 cycles of $\mathrm{PCR}\left(95^{\circ} \mathrm{C}\right.$ for 30 seconds, $63^{\circ} \mathrm{C}$ for 30 seconds, and $72^{\circ} \mathrm{C}$ for 30 seconds) followed by a 7 -minute final extension at $72^{\circ} \mathrm{C}$. Ethanol precipitation was done on the PCR products, and then samples were sent for Sanger sequencing (GENEWIZ, Inc., Plainfield, NJ).

Behavioral Assessment. Male and female Gnao1 ${ }^{+/ R 209 H}$ mice (8-12 weeks of age) and their Gnao $1^{+/+}$littermates underwent a battery of behavioral testing to assess motor phenotype as described previously (Feng et al., 2019). Before each experiment, mice were acclimated for 10 minutes to the testing room. Experiments were performed by two female researchers. All behavioral studies were done by individuals who were blind to the genotype of the animals until completion of data collection.

Open Field. The open field test is frequently used to assess locomotion, exploration, and anxiety (Tatem et al., 2014; Seibenhener and Wooten, 2015; Feng et al., 2019). The test was conducted in Fusion VersaMax clear $42 \times 42 \times 30 \mathrm{~cm}$ arenas (Omnitech Electronics, Inc., Columbus, OH). Gnao $1^{+/ R 209 H}$ mice of both sexes and their littermates were placed in the arena for 30 minutes. Using the Fusion Software, we evaluated distance traveled $(\mathrm{cm})$ in terms of novelty, sustained, and total movement corresponding to the first 10 minutes, 10-20 minutes, and total of 30 minutes. As a potential measure of anxiety, the fraction of time spent in the center was assessed. The center area was defined as the $20.32 \times 20.32 \mathrm{~cm}$ area within the middle of the arena.

Rotarod. To assess motor skills, we used the Economex accelerating RotaRod (Columbus Instruments, Columbus, $\mathrm{OH}$ ). The protocol occurred over a 2 -day period. On day 1 , mice were trained for three 
A

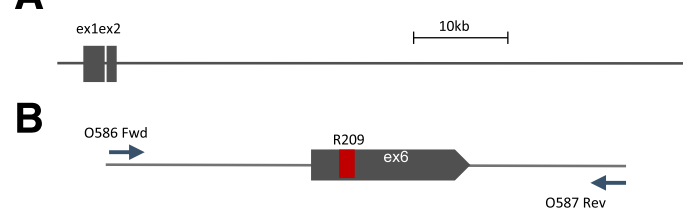

D

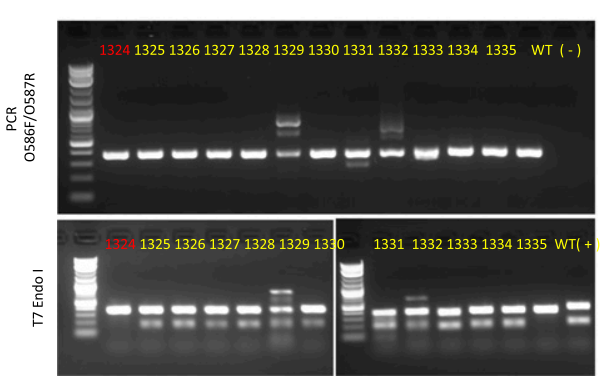

C

CTGACTCCCTGCAGGCTGTTTGACGTCGGGGGCCAGCGATCTGAACGCAAGAAGTGGATCCACTGCTTTGAGGATGTCACGGCCATCATCTTCTGTGTCGCA GACTGAGGGACGTCCGACAAACTGCAGCCCCCGGTCGCTAGACTTGCGTTC:TCACCTAGGTGACGAAACTCCTACAGTGCCGGTAGTAGAAGACACAGCGT E

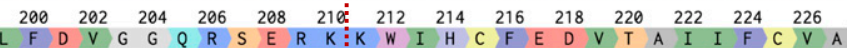

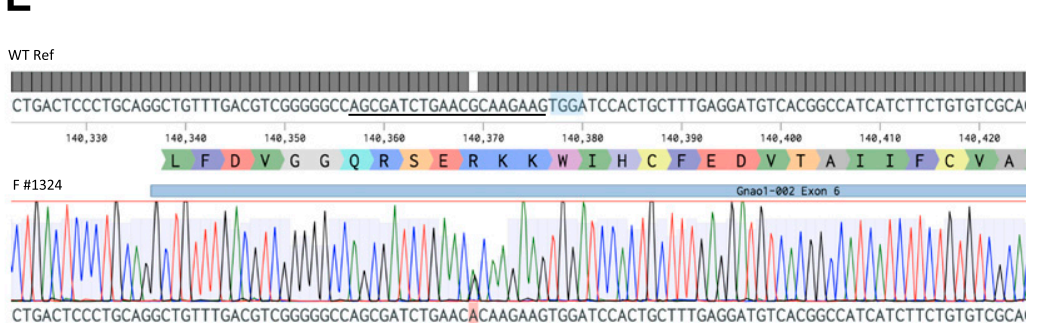

Fig. 1. Targeting of the mouse Gnao1 locus. (A) Mouse Gnao1 genomic locus (exon size not to scale), red outline is magnified in (B) showing exon 6 and relative location of codon 209 and PCR primers O586 and O587. (C) Location and exact sequence of gRNA target within exon 6, dotted red line denotes double-strand DNA break, protospacer-adjacent motif (PAM) is highlighted and sequence corresponding to gRNA protospacer is underlined [also in (E)]. (D) Raw gel electrophoresis images showing PCR of the target region and T7 Endonuclease I (T7 Endo I) digestion analysis of founders 1324-1335 $(n=12)$, with WT, $\mathrm{H}_{2} \mathrm{O}(-)$, and T7Endo I (+) controls. Founder 1324 (red number) was positive for the mutation on one allele and WT on the other; note that the single bp mismatch was not reliably detected by T7 Endo I assay. (E) Exact sequence of edited founder 1324 as aligned to WT reference genome, two peaks (G and A) are detected on the sequence chromatogram, indicating the presence of both WT and edited R209H allele. Endo, endonuclease; Ex, exon; Fwd, forward; Ref, reference; Rev, reverse.

2-minute training sessions, with 10 minutes between each training trial. During the first two sessions, the RotaRod maintained a constant rotational speed of $5 \mathrm{rpm}$. The third training trial started at $5 \mathrm{rpm}$ and accelerated at $0.1 \mathrm{rpm} / \mathrm{s}$ for 2 minutes. The following day, mice ran three more trials with a 10-minute break in between: two more 2-minute training trials and a final 5-minute test trial. Each of these trials started at $5 \mathrm{rpm}$ with constant acceleration of $0.1 \mathrm{rpm} / \mathrm{s}$. For all training and test trials, latency to fall off the spindle was recorded in seconds.

Grip Strength. To assess mouse grip strength, we used seven homemade weights $(10,18,26,34,42,49$, and $57 \mathrm{~g})$ with a $2.54-\mathrm{cm}$ ring for the mouse to grasp. The mouse was held by the middle/base of the tail and lowered to the weight. Once the mouse grasped the weighted ring with its forepaws, the mouse was lifted until the weight cleared the bench. For each weight, the mouse was given up to three trials to suspend the weight above the table for 3 seconds. If cleared, the next heaviest weight was tried. If the weight was not held, the total time and maximum weight lifted were recorded, and a grip strength score was calculated from Deacon et al. (2016). The calculated score was normalized to mouse body weight, which was measured the day of the test.

DigiGait. Mouse gait analysis was performed on a DigiGait apparatus (Mouse Specifics, Inc, Framingham, MA). After acclimation, each mouse was placed on the treadmill at speeds of $18,20,22,25$, 28,32 , and $36 \mathrm{~cm} / \mathrm{s}$. A 10 -second clip was recorded with a video camera located below the belt. There was a 5-minute rest between each speed. Recordings were analyzed with the DigiGait analysis program to assess the prespecified parameters of stride length and paw angle variability. Values for all four paws were averaged to give one value per mouse- the reported $n$ values are the number of mice. In addition, the maximum speed at which each mouse was able to successfully complete a 10-second test after three attempts was recorded as described (Feng et al., 2019).

PTZ Kindling Study. A PTZ kindling protocol was performed as described (Kehrl et al., 2014; Feng et al., 2019) to assess mouse susceptibility to seizure induction. Mice were injected with a subconvulsive dose of PTZ (40 mg/kg, i.p.) every other day for up to 24 days, and mice then were observed for 30 minutes postdose. Kindling was defined as death or tonic-clonic seizures on two consecutive injection days, after which mice were euthanized. Kaplan-Meier survival analysis was done based on the number of injections to achieve kindling.

G $\boldsymbol{\alpha}_{\mathbf{o}}$ Protein Expression. Mice (6-8 weeks old) were sacrificed, and their brains were dissected into different regions and flash-frozen in liquid nitrogen. For Western blot analysis, tissues were thawed on ice and homogenized for 5 minutes with $0.50-\mathrm{mm}$ zirconium beads in a Bullet Blender (Next Advance, Troy, NY) in radioimmunoprecipitation assay (RIPA) buffer (20 mM Tris-HCl, pH7.4; $150 \mathrm{mM} \mathrm{NaCl} ; 1 \mathrm{mM}$ EDTA; $1 \mathrm{mM} \beta$-glycerophospate; $1 \%$ Triton X-100; and 0.1\% SDS) with protease inhibitor (Roche/ 1 tablet in $10 \mathrm{ml}$ RIPA). Sample homogenates were centrifuged for 5 minutes at $4^{\circ} \mathrm{C}$ at $13,000 \mathrm{~g}$. Supernatants were collected and protein concentrations determined using the bicinchoninic acid method (Pierce, Rockford, IL). Protein concentration was normalized for all tissues with RIPA buffer, and $2 \times$ SDS sample buffer containing $\beta$-mercaptoethanol (Sigma-Aldrich) was added. Thirty micrograms of protein was loaded onto a $12 \% 2$ [bis(2-hydroxyethyl)amino]-2-(hydroxymethyl)propane-1,3-diol SDSPAGE gel, and samples were separated for 1.5 hours at $160 \mathrm{~V}$. Proteins were then transferred to an Immobilon-FL polyvinylidene

TABLE 1

Location and sequence of gRNA and ssODN template for CRISPR-Cas targeting Gnao1 locus; primers and genotyping method for Gnao $1^{+T_{R 2 O 9 H}}$ mice

\begin{tabular}{lc}
\hline Location & $\begin{array}{c}\text { Gnao1 R209H } \\
\text { Chr 8: 93,950,334 }\end{array}$ \\
\hline $\begin{array}{c}\text { gRNA target 5' N20-PAM } \\
-3^{\prime}\end{array}$ & 5' AGCGATCTGAACGCAAGAAG TGG 3' \\
ssODN template (reverse & GTTTCGTCCTCGTGGAGCACCTGG \\
complement) & TCATAGCCGCTGAGTGCGACACAG \\
& AAGATGATGGCCGTGACATCCTCA \\
& AAGCAGTGGATCCACTTCTTGtGT \\
& TCAGATCGCTGGCCCCCGACGTCA \\
& AACAGCCTGCAGGGAGTCAGGGAA \\
PCR primers & AGCTGTGAGGGCGGGGACGCCTA \\
& O586 FWD: 5' GGACAGGTGTCACAG \\
Genotyping & GGGAT 3' O587 REV: 5' ACTGGCCTC \\
\hline
\end{tabular}

Chr, chromosome; FWD, forward; PAM, protospacer-adjacent motif; REV, reverse. 
difluoride membrane (Millipore, Billerica, MA) on ice either for 2 hours at $100 \mathrm{~V}, 400 \mathrm{~mA}$ or overnight at $30 \mathrm{~V}, 50 \mathrm{~mA}$. Immediately after transfer, polyvinylidene difluoride membranes were washed and blocked in Odyssey PBS blocking buffer (LI-COR) for 40 minutes at room temperature. The membranes were then incubated with anti-G $\alpha$ o (rabbit; 1:1000; sc-387; Santa Cruz biotechnologies, Santa Cruz, CA) and anti-actin (goat; 1:1000; sc-1615; Santa Cruz) antibodies diluted in Odyssey blocking buffer with $0.1 \%$ Tween-20 overnight at $4^{\circ} \mathrm{C}$. Following four 5-minute washes in phosphatebuffered saline with $0.1 \%$ Tween-20, the membrane was incubated for 1 hour at room temperature with secondary antibodies (both 1 : 10,000; IRDye 800CW Donkey anti-rabbit; IRDye 680RD Donkey anti-goat; LI-COR Biosciences) diluted in Odyssey blocking buffer with $0.1 \%$ Tween-20. The membrane was subjected to four 5 -minute washes in PBS-Tween-20 and a final rinse in PBS for 5 minutes. The membrane was kept in the dark, and the infrared signals at 680 and $800 \mathrm{~nm}$ were detected with an Odyssey Fc image system (LI-COR Biosciences). The $\mathrm{G} \alpha_{\mathrm{o}}$ polyclonal antibody recognizes an epitope located between positions 90-140 G $\alpha_{\mathrm{o}}$ (Santa Cruz Technical Support, personal communication), so there should be no interference from the $\mathrm{R} 209 \mathrm{H}$ mutation.

Kinetics of Nucleotide Binding. To estimate GDP release rates, which can control activation of $\mathrm{G}$ proteins, we measured the kinetics of binding of the fluorescent ligand 4-4-difluoro-5,7-dimethyl-4-bora3a,4a-diaza-s-indacine-3-yl (BODIPY-FL)-GTP $\gamma \mathrm{S}$ as described previously (McEwen et al., 2002). In brief, WT and mutant His6-tagged $\mathrm{G} \alpha_{\mathrm{o}}$ subunits were expressed in Escherichia coli and purified by Ninitrilotriacetic acid affinity chromatography as previously described (Lee et al., 1994) and stored frozen at -80 C in $50 \mathrm{mM}$ HEPES $100 \mathrm{mM}$ $\mathrm{NaCl}$ buffer containing $50 \mu \mathrm{M}$ GDP to stabilize the protein. Protein was diluted to $200 \mathrm{nM}$ in binding buffer (50 mM HEPES, $10 \mathrm{mM}$ $\mathrm{MgCl}_{2}, 1 \mathrm{mM}$ EDTA, and $1 \mathrm{mM}$ dithiothreitol, $\mathrm{pH}$ 8.0), and then 100 $\mathrm{nM}$ BODIPY-GTP $\gamma \mathrm{S}$ was added, and fluorescence was monitored at $485 \mathrm{~nm}$ excitation, $510 \mathrm{~nm}$ emission in a Tecan Infinite M1000 Pro microplate reader at $24^{\circ} \mathrm{C}$. Experiments were done on three different days each in duplicate, and results were averaged. Rate constants and $\mathrm{t}_{1 / 2}$ were determined by fitting results to the equation $\mathrm{Y}=\mathrm{Y} 0+$ $(\mathrm{Ymax}-\mathrm{Y} 0) *\left(1-\mathrm{e}^{-\mathrm{k} * \mathrm{t}}\right)$ in GraphPad Prism v. 8, in which Y0 was constrained to be shared between the WT and R209H mutant data sets.

Risperidone Effects on Motor Behavior. Naïve 8-12-week-old Gnao1 $1^{+/ R 209 H}$ and Gnao $1^{+/+}$littermates of either sex were tested for effects of risperidone on their activity in the open field arena. The study was run over 5 days: On day 1 , mice underwent the open field protocol described above to establish a baseline. On day 3, mice were habituated in the experimental room for 10 minutes and then given a single intraperitoneal dose of $2.0 \mathrm{mg} / \mathrm{kg}$ risperidone (Cayman Chemical, Ann Arbor, MI) or vehicle control. Risperidone was dissolved in DMSO at a concentration of $5 \mathrm{mg} / \mathrm{ml}$, and further dilutions were done in deionized water. Thirty minutes following injection, mice were placed in the open field arena for a 30-minute testing time. On day 5 , mice were retested in the same open field protocol without injection to assess drug washout. A week later, the same protocol was followed to test the effects an intraperitoneal dose of $0.5 \mathrm{mg} / \mathrm{kg}$ risperidone had on the WT and $\mathrm{R} 209 \mathrm{H}$ mice.

Statistical Analysis. Data were analyzed with unpaired Student's $t$ test or Mantel-Cox and two-way ANOVA with Bonferroni corrections as appropriate using GraphPad Prism 7.0 (GraphPad, La Jolla, CA). A $P<0.05$ was considered the cutoff for significance throughout. Detailed discussion of statistical analyses can be found within figure legends.

\section{Results}

Gnao1 $^{+/ R 209 H}$ Mice Are Produced at the Expected Frequency and Have Normal Viability. Two founder Gnao $1^{+/ R 209 H}$ mice, one male and one female, were crossed with C57BL/6J mice. Out of 98 offspring of a cross of Gnao $^{+/ R 209 H}$ with WT mice, 51 heterozygotes and 47 WT were observed. Gnao $1^{+/ R 209 H}$ mice exhibit no overt postural or movement abnormalities or seizures under normal housing conditions. Adult mice showed no statistically significant differences in weight between WT and Gnao1 $1^{+/ R 209 H}$ genotypes of either sex.

Both Male and Female Gnao1 ${ }^{+/ R 209 H}$ Show Significant Hyperactivity in the Open Field Arena but No Significant Differences on the Rotarod or Grip Strength Test. Patients with R209H mutations present with hyperkinetic movement disorders (Ananth et al., 2016; Dhamija et al., 2016; Menke et al., 2016). To detect motor abnormalities, Gnao $1^{+/ R 209 H}$ mice were subjected to a battery of behavioral tests. The open field arena was used to test overall locomotor activity. We divided the test into two sections reflecting activity in a novel environment (0-10 minutes) and then sustained activity (10-30 minutes). Gnao $1^{+/ R 209 H}$ mice of both sexes showed markedly increased activity in the sustained activity period compared with their wild-type littermates (Fig. 2B). Females also had significantly increased activity in the first 10 minutes (novelty period, Fig. 2B). As a potential indicator of anxiety-like behavior, male and female Gnao1 $1^{+/ R 209 H}$ mice also displayed reduced time in center (Fig. 2, A and B).

An accelerating RotaRod test was used to assess motor coordination and balance. Neither male nor female Gnao $1^{+/ R 209 H}$ mice displayed impaired performance (Fig. 2C). Also, grip strength showed no differences between Gnao1 $1^{+/ R 2 O 9 H}$ and wild-type littermates of either sex (Fig. 2D).

Male Gnao1 ${ }^{+/ R 209 H}$ Mice Display a Modestly Reduced Stride Length. Gait patterns were assessed using DigiGait analysis. Male Gnao $1^{+/ R 209 H}$ mice (Fig 3, B) showed a highly significant genotype effect with reduced stride length compared with wild-type littermates $(P<0.001$, two-way ANOVA), but the magnitude of the effect was modest (5.6\% decrease averaged across all speeds). In posttest analysis, only the top speed $(36 \mathrm{~cm} / \mathrm{s})$ reached significance individually $(P<0.01)$. Female Gnao $1^{+/ R 209 H}$ mice did not show significant differences in stride length from WT (Fig. 3, A). However, as previously reported for G203R mutant mice, the female Gnao1 $1^{+/ R 209 H}$ showed a significantly reduced maximum run speed on the treadmill (Fig. 3E $P<0.01, t$ test). This was not due to reduced body size because length, as detected by the DigiGait system (WT $9.54 \mathrm{~cm}$ : vs. R209H $10.17 \mathrm{~cm}$ ), and weights were not significantly different. There was no significant difference in paw angle variability for either males or females. All parameters of DigiGait analysis are shown in Supplemental Tables 3 and 4, and false discovery rate calculation probed of significantly different parameters from the DigiGait data in Gnao $1^{+/ R 209 H}$ mice is shown in Supplemental Fig. 2.

Gnao1 $^{+/ R 209 H}$ Mice Are Not Sensitive to PTZ Kindling. Repeated application of a subthreshold convulsive stimulus leads to the generation of full-blown convulsions in a process called kindling (Dhir, 2012). GNAO1 variants differ in their ability to cause epileptic seizures in patients. Those carrying the $\mathrm{R} 209 \mathrm{H}$ mutant allele do not exhibit a seizure disorder (Ananth et al., 2016; Kulkarni et al., 2016; Menke et al., 2016). In accordance with the patients' pattern, Gnao1 ${ }^{+/ R 209 H}$ mice did not show increased susceptibility to 
A

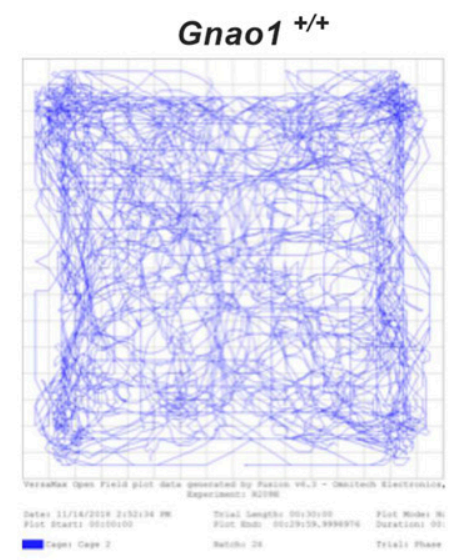

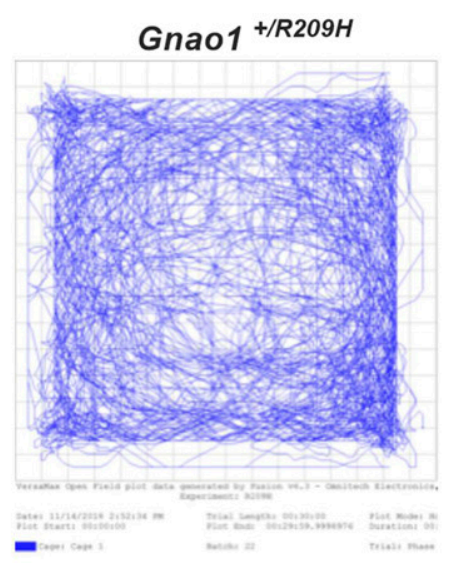

B

Open Field

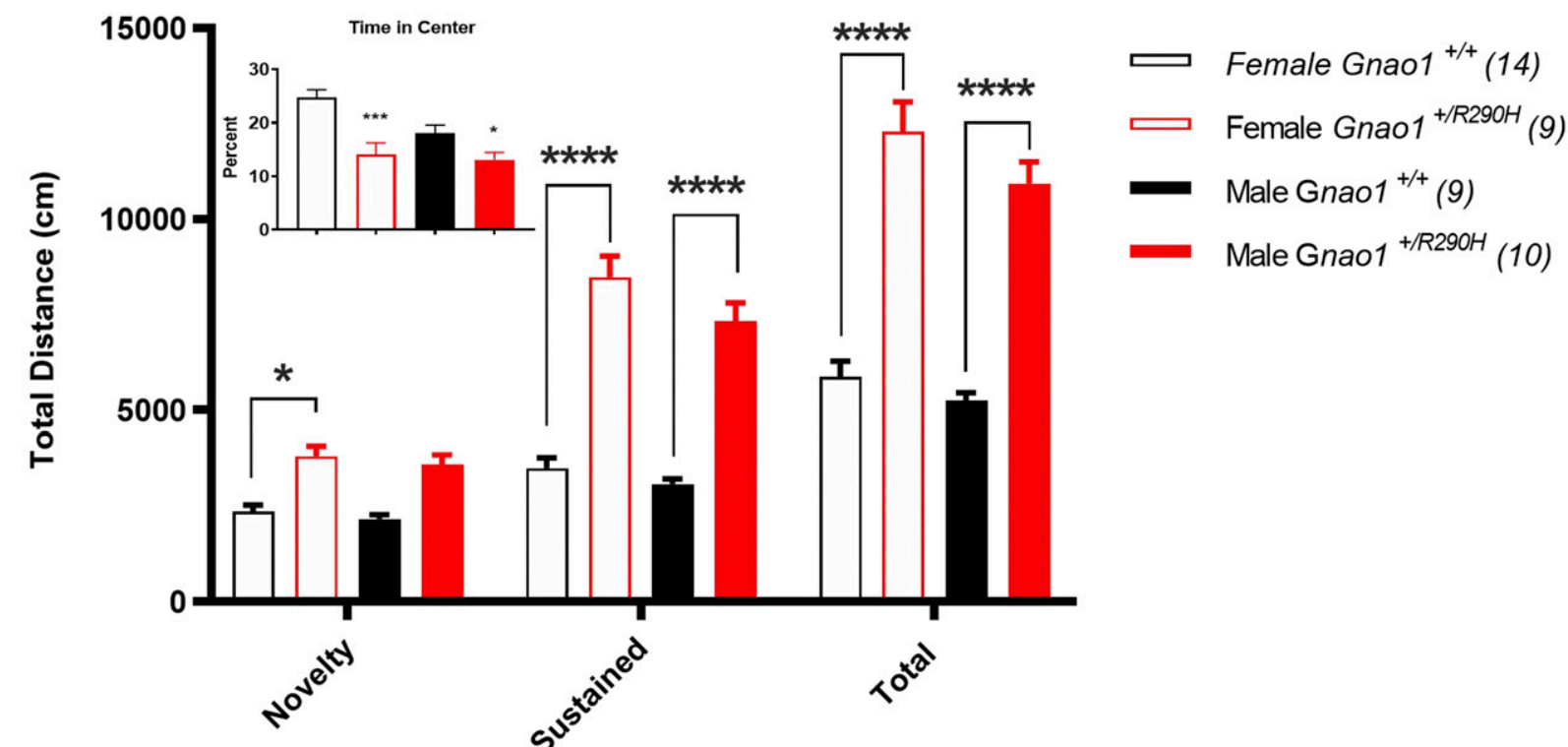

C

Rotarod Test

D Grip Strength Body Weight/Score
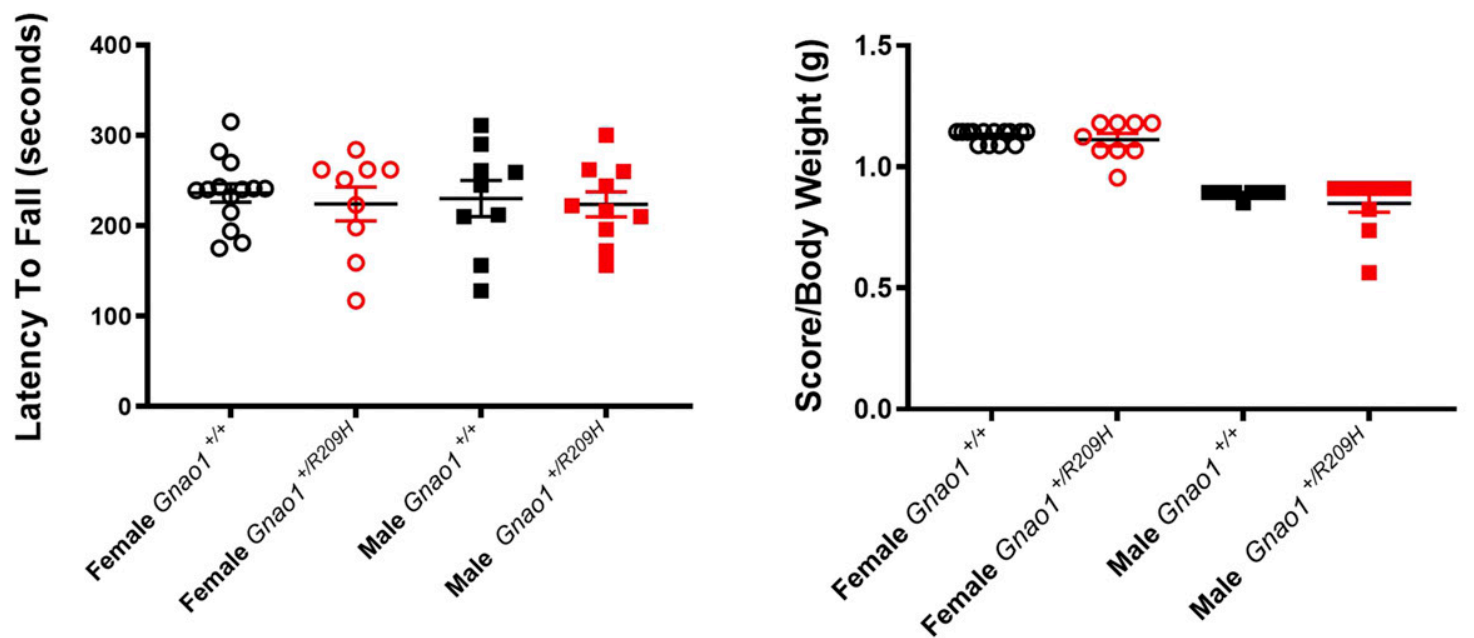

Fig. 2. Gnao $1^{+/ R 209 H}$ mice show significant hyperactivity and reduced time in center in the open field arena. (A) Representative heat maps of Gnao $1^{+/ R 209 H}$ mice and Gnao $1^{+/+}$mice in the open field arena. (B) Time spent in the open field arena was separated into 0-10 minutes (novelty) and 10-30 minutes (sustained). Gnao1 $1^{+/ R 209 H}$ male and female mice exhibit increased locomotion in the novelty period. Hyperactivity observed in the sustained period and for total travel time (two-way ANOVA; $* P<0.05 ; * * P<0.001 ; * * * P<0.0001$ ). Female R209H mutant mice also showed significantly greater distance traveled in the novelty period $(* P<0.05)$. Gnao ${ }^{+/ R 209 H}$ mice of both sexes spend less time in center areas of the open field arena compared with wild-type littermates. (C) Neither male nor female Gnao1 ${ }^{+/ R 209 H}$ mice show significant differences on the RotaRod. (D) There is also no significant difference in grip strength between wild-type and Gnao1 ${ }^{+/ R 209 H}$ mice. Data are shown as mean \pm S.E.M. 
A

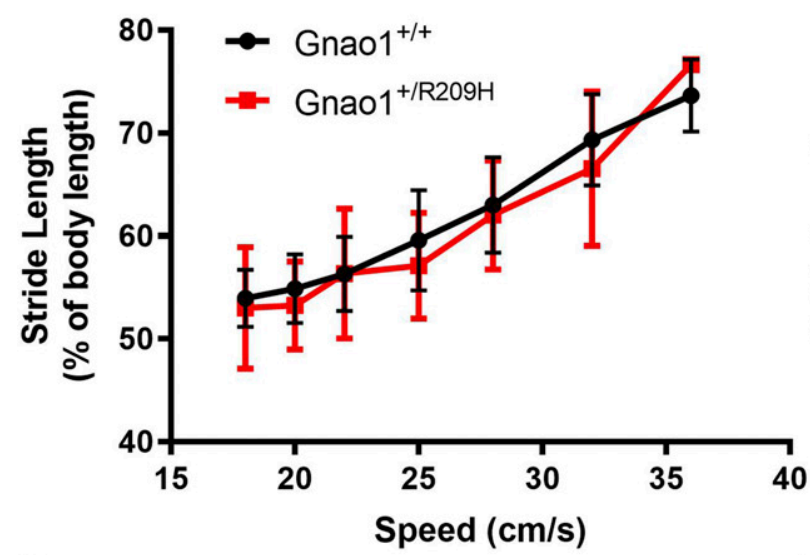

C

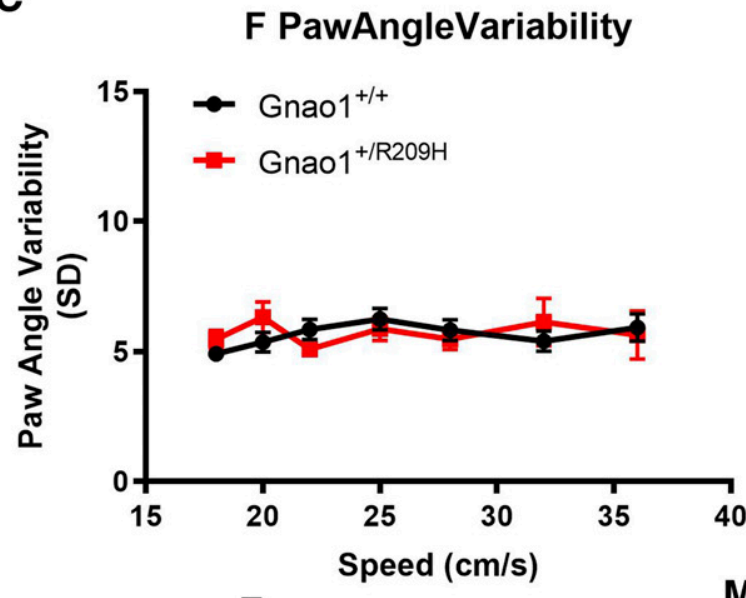

B

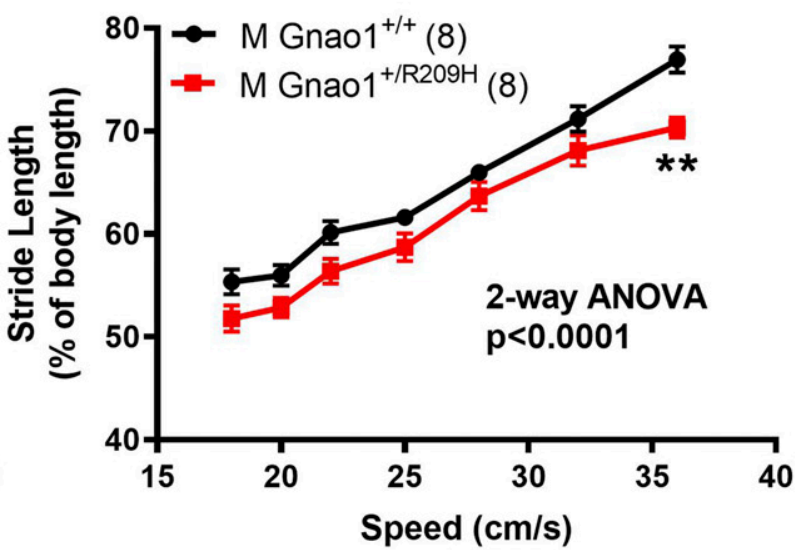

D

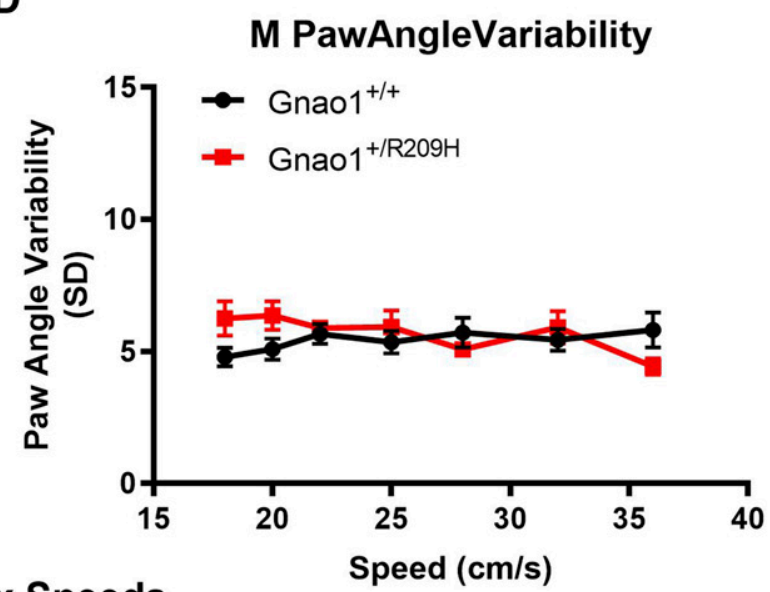

E

\section{Max Speeds}

Fig. 3. Male and female Gnao $1^{+/ R 209 H}$ mice shows gait abnormalities in different tests on the DigiGait imaging system. (B) Male Gnao $1^{+/ R 209 H}$ mice showed reduced stride length compared with wild-type littermates (two-way ANOVA with Bonferroni multiple comparison posttest), whereas female Gnao $1^{+/ R 209 H}$ mice showed a normal stride length. (A) Neither male nor female Gnao $1^{+/ R 209 H}$ exhibited significant differences in paw angle variability (C and D) compared with wild-type littermates. (E) At speeds greater than $25 \mathrm{~cm} / \mathrm{s}$, female $G n a o 1^{+/ R 209 H}$ had a reduced ability to run on the treadmill. F, female; $\mathrm{M}$, male. ** $\mathrm{P}<0.01$.

kindling-induced seizures (Fig. 4). This contrasts with our previous report of increased kindling sensitivity in male G203R and female G184S mutant mice (Kehrl et al., 2014; Dhamija et al., 2016; Feng et al., 2019).

Gnao1 $^{+/ R 209 H}$ Mice Have Normal G $\alpha_{\mathrm{o}}$ Protein Expression in the Brain. To understand why R209H mutant mice do not show a phenotypic difference in the kindling test while G203R mutants do, we assessed $\mathrm{G} \alpha_{\mathrm{o}}$ protein expression levels.
Cortex, hippocampus, striatum, cerebellum, brain stem, and olfactory bulb were harvested and homogenized to measure the effect of the $\mathrm{R} 209 \mathrm{H}$ mutation on $\mathrm{G} \alpha_{\mathrm{o}}$ protein expression. Western blots showed no difference in $\mathrm{G} \alpha$ o protein expression between WT and Gnao1 $1^{+/ R 209 H}$ mice in any of the measured brain regions (Fig. 5, A and B). This is consistent with our previous analysis of protein expression in HEK293T cells with transiently transfected $\mathrm{G} \alpha_{\mathrm{o}} \mathrm{R} 209 \mathrm{H}$ plasmid (Feng et al., 


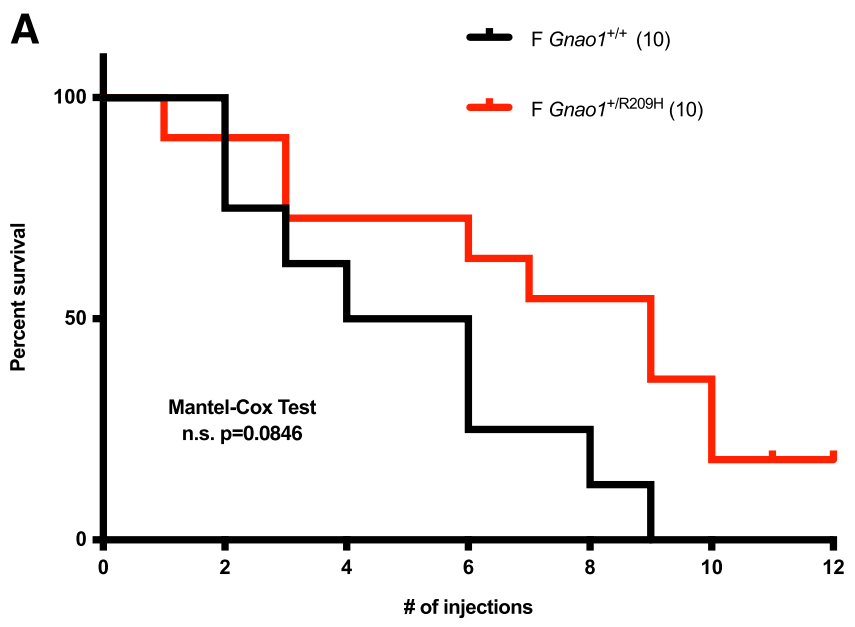

B

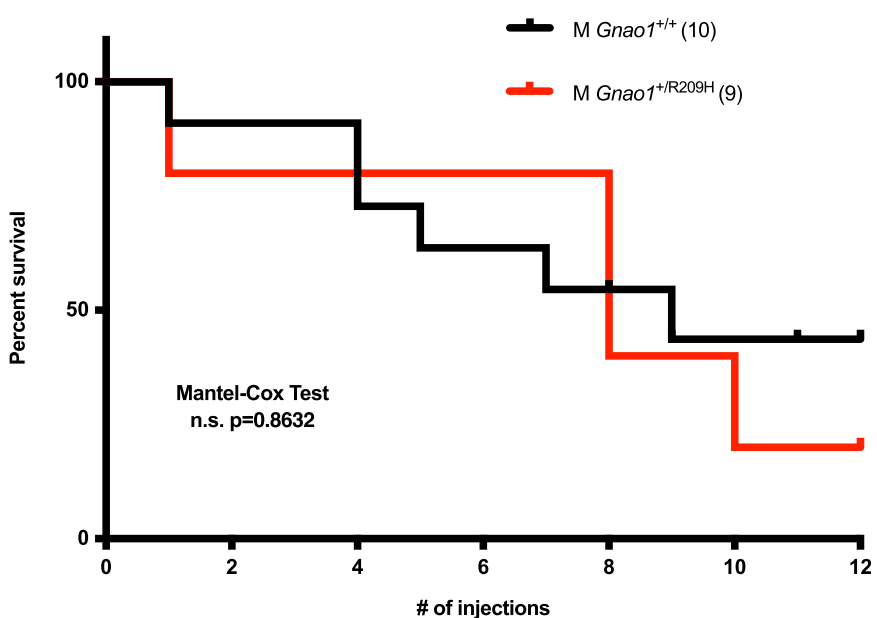

Fig. 4. Gnao $1^{+/ R 209 H}$ mice do not have an enhanced PTZ kindling response. (A and B) Neither male nor female Gnao $1^{+/ R 209 H}$ mice showed significant differences in sensitivity to PTZ injection compared with wildtype littermates (n.s. Mantel-Cox test). F, female; M, male; n.s., not significant.

2017). The normal expression of the R209H mutant contrasts with the reduced expression of $\mathrm{G} \alpha_{\mathrm{o}}$ in brains of $\mathrm{G} \alpha_{\mathrm{o}}{ }^{+/ \mathrm{G} 203 \mathrm{R}}$ mutant mice (Feng et al., 2019).

Kinetics of Nucleotide Binding to Mutant $\mathbf{G} \alpha_{\mathrm{o}}$. Both patients and mice heterozygous for the $\mathrm{G} \alpha_{\mathrm{o}} \mathrm{R} 209 \mathrm{H}$ mutation display movement phenotypes; however, the mutant $\mathrm{G} \alpha_{\mathrm{o}}$ supports normal cAMP regulation in the cell-based cAMP assay (Feng et al., 2017). To consider possible mechanisms for this discrepancy, we measured the rate of GDP release from mutant $\mathrm{G} \alpha$ o using the BODIPY-GTP $\gamma \mathrm{S}$ binding kinetics method (McEwen et al., 2002). The rate of GTP $\gamma \mathrm{S}$ binding to WT G $\alpha_{\mathrm{o}}$ was slow ( $\mathrm{T}_{1 / 2} 1261$ seconds, Fig. $5 \mathrm{C}$ ), as expected. The $\mathrm{R} 209 \mathrm{H}$ mutant $\mathrm{G} \alpha_{\mathrm{o}}$ showed markedly faster binding of BODIPY-GTP $\gamma \mathrm{S}\left(\mathrm{T}_{1 / 2} 203\right.$ seconds $6.2 \times$ faster than WT, Fig. 5, C and D), suggesting a faster rate of GDP release. In addition to the faster rate of binding, the amplitude of binding was lower for the R209H mutant. Though this lower amplitude of binding might be due to either a lower affinity of the mutant for the BODIPY-GTP $\gamma \mathrm{S}$ or to instability under the binding conditions, we do show that the R209H mutant definitely does have abnormal interactions with nucleotidesGDP and/or GTP.
Risperidone Treatment Attenuated the Hyperactivity of Gnao1 ${ }^{+/ R 209 H}$ Mice. Patients with GNAO1 mutations were tried on multiple drugs to alleviate motor symptoms (Supplemental Table 1). Risperidone, an atypical antipsychotic drug, showed beneficial effects in one of the patients. It has also been effective in drug-induced dyskinesia (Carvalho et al., 2003). We show that Gnao1 $1^{+/ R 209 H}$ mice exhibit complete abrogation of movement at $2 \mathrm{mg} / \mathrm{kg}$ risperidone, which recovered upon retesting 2 days later (Fig. 6, A and C). WT mice also show a significant decrease in locomotion after $2 \mathrm{mg} / \mathrm{kg}$ risperidone treatment (Fig. 6A). After a single $0.5 \mathrm{mg} / \mathrm{kg}$ dose of risperidone, both WT and $G n a o 1^{+/ R 209 H}$ mice exhibit a decrease in locomotion compared with vehicletreated littermates (Fig. 6B). As expected, hyperactivity of mutant mice was observed during baseline testing on day 1 , and the hyperactivity had returned on day 5 following the 2-day washout period after the risperidone doses (Fig. 6C). Neither $2.0 \mathrm{mg} / \mathrm{kg}$ nor $0.5 \mathrm{mg} / \mathrm{kg}$ selectively affected Gnao $1^{+/ R 209 H}$, as assessed by percent suppression of distance traveled (Supplemental Fig. 1).

\section{Discussion}

We have developed a novel mouse model carrying an $\mathrm{R} 209 \mathrm{H}$ mutation in the Gnao1 gene that leads to a serious movement disorder (Ananth et al., 2016; Dhamija et al., 2016). Though GNAO1 mutations are rare in humans, the $\mathrm{R} 209 \mathrm{H}$ mutation is the second most common found in patients with GNAO1-related disorders. The mice have a clear movement phenotype confirming the pathologic nature of this mutation despite earlier work showing that it could normally support receptor-mediated regulation of cAMP in HEK cells (Feng et al., 2017). This model will provide a powerful tool to both understand neural mechanisms of the dysfunction of the $\mathrm{R} 209 \mathrm{H} \mathrm{G} \alpha_{\mathrm{o}}$ protein as well as permit preclinical drug repurposing studies.

The goal of personalized medicine is to define treatments for an individual patient. Knowing which gene is involved is beneficial, but different mutant alleles, even in the same gene, can produce quite distinct effects. Here we report a second mouse model of GNAO1-related neurologic abnormalities. The Gnao1 R209H mutant mice display motor abnormalities but no seizures, which differs from our previous Gnao1 G203R mouse model (Feng et al., 2019). This is consistent with the clinical pattern of patients with GNAO1 R209H, who present with neurodevelopmental delay with involuntary movements without seizures (Ananth et al., 2016; Dhamija et al., 2016).

The specific movement abnormalities seen with the Gnao1 $\mathrm{R} 209 \mathrm{H}$ mutant mice were somewhat unexpected; our previous mouse model, Gnao1 $1^{+/ G 203 R}$, showed significant motor impairments in RotaRod and DigiGait but had no changes in the open field test (Feng et al., 2019). In contrast, the Gnao1 $\mathrm{R} 209 \mathrm{H}$ mutant mice reported here have profound hyperactivity in the open field test and either no or only modest deficits in RotaRod and DigiGait analysis. Patients with the G203R or $\mathrm{R} 209 \mathrm{H}$ mutations both display movement disorder, with choreathetosis and dystonia as the most common patterns (Saitsu et al., 2016; Feng et al., 2018). Interestingly, patients with the $\mathrm{R} 209 \mathrm{H}$ mutation have somewhat more choreoathetosis compared with those with the G203R mutation, although they display similar frequencies of dystonia (Feng et al., 2018). Such differences in patient phenotype may relate to the 
A

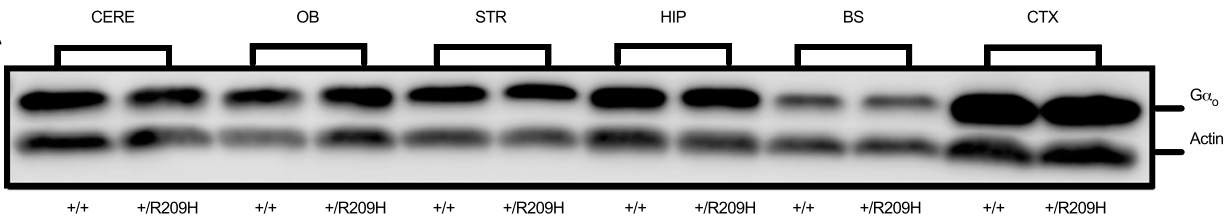

B

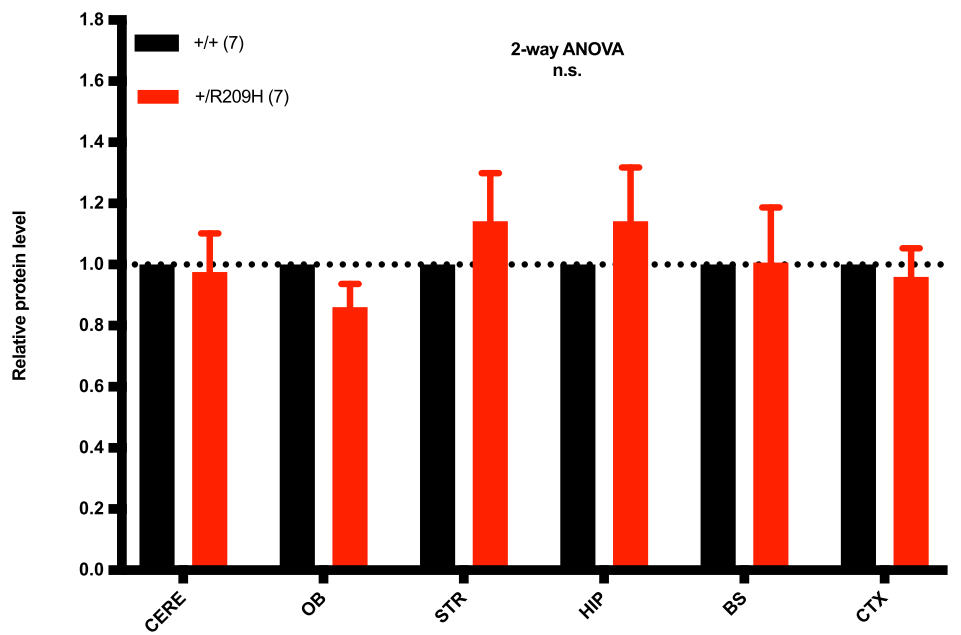

C

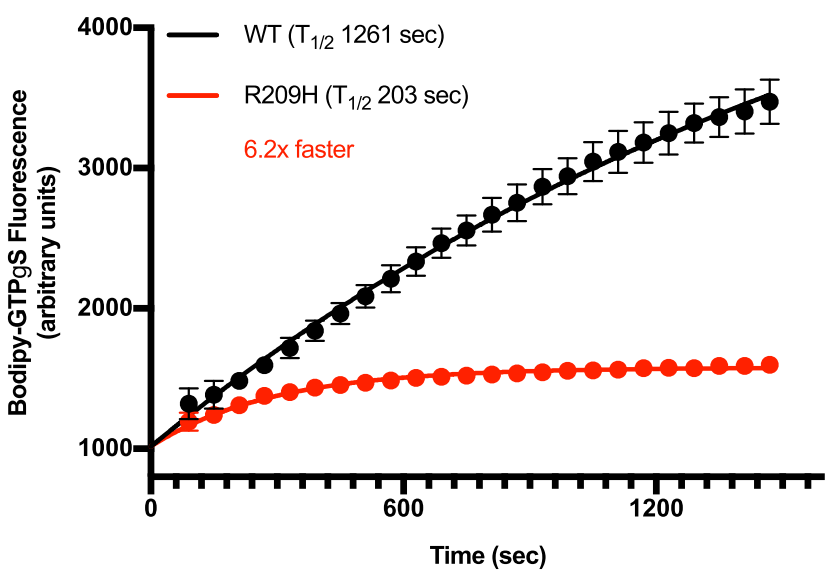

D

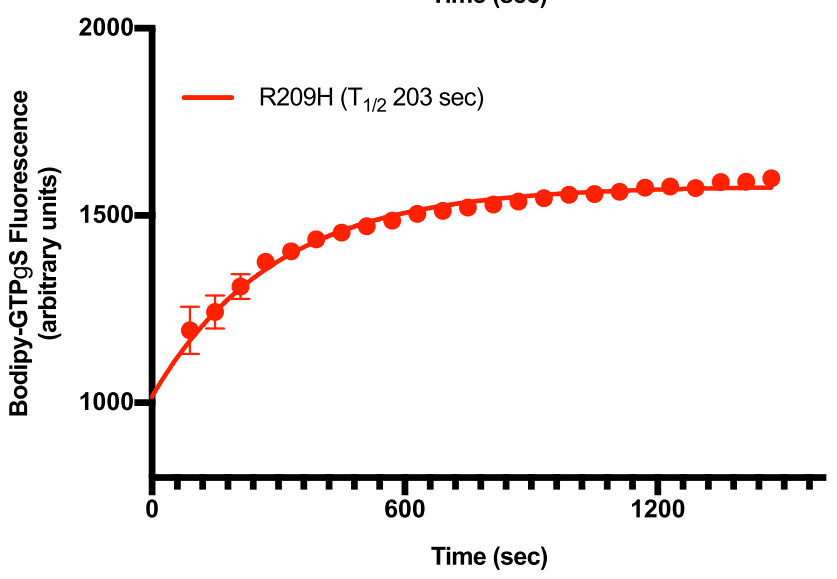

Fig. 5. Biochemical analysis of brain $\mathrm{G} \alpha$ 。 protein levels and in vitro nucleotide exchange for WT and $\mathrm{R} 209 \mathrm{H}$ mutant $\mathrm{G} \alpha_{\mathrm{o}}$. (A) Brain regions (cortex, hippocampus, striatum, cerebellum, brain stem, and olfactory bulb homogenates) from WT and Gnao $1^{+/ R 209 H}$ mice were assessed by Western blot for levels of $\mathrm{G} \alpha_{0}$ protein. (B) Protein levels of Gnao $1^{+/ R 209 H}$ brain samples were quantified using LI-COR IRDye staining, and values were normalized to actin levels and then to the control sample from WT run on the same day. There was no significant difference in any of the regions between WT and mutant mice $(n=7)$. (C and D) The kinetics of BODIPY-FLGTP $\gamma \mathrm{S}$ binding were measured as described in Materials and Methods. The time course of the fluorescence increase was fit to an exponential function (connecting lines) and the T1/2 calculated from the rate constant of the exponential function (see Materials and Methods). Nucleotide binding experiments were performed in duplicate, and results from the separate days were averaged. Error bars and mean \pm S.D. $(n=3)$. For some data points, error bars are smaller than the symbol and are not shown. BS, brain stem; CERE, cerebellum; CTX, cortex; HIP, hippocampus; n.s., not significant; $\mathrm{OB}$, olfactory bulb; STR, striatum; $\mathrm{T}_{1 / 2}$, half-time; WT, wild-type.

differences in the animal models' behavior. In looking at the behavior of the R209H model specifically, the striking hyperactivity of the male $\mathrm{R} 209 \mathrm{H}$ mutant mice points to increased dopamine signaling in the striatum as a possible mechanism. Suppression of that hyperactivity with risperidone is consistent with that mechanism.
The two movement disorder-associated GNAO1 mutations $\mathrm{R} 209 \mathrm{H}$ and G203R also have different patterns in in vitro studies of cAMP regulation in HEK293T cells (Feng et al., 2017). Interestingly, the $\mathrm{G} \alpha_{\mathrm{o}} \mathrm{R} 209 \mathrm{H}$ mutant supports normal cAMP regulation and is expressed at normal levels both in HEK cells (Feng et al., 2017) and in the brain (this study). 


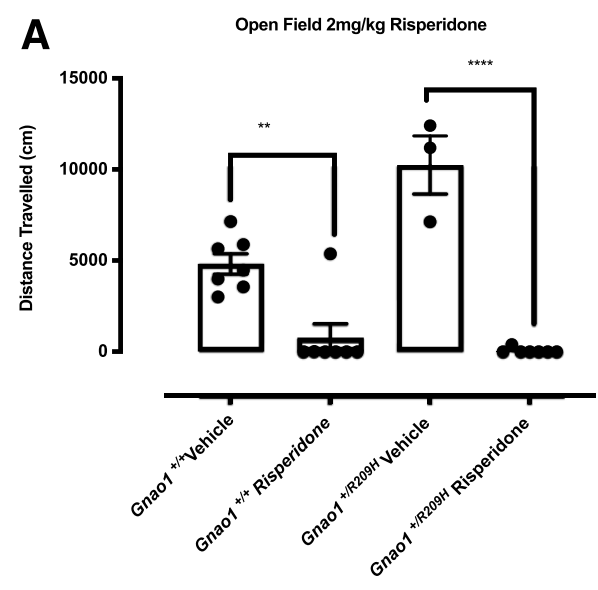

C

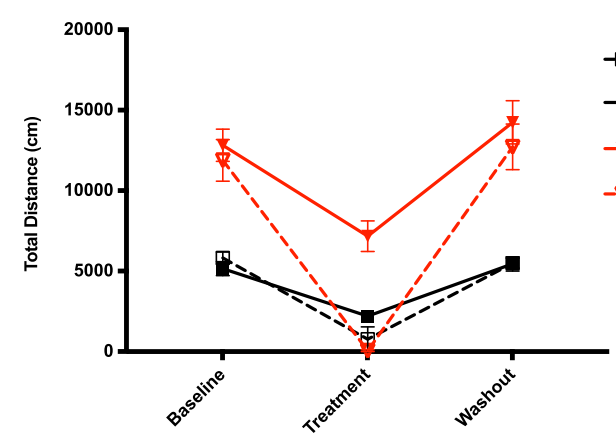

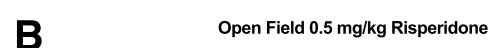

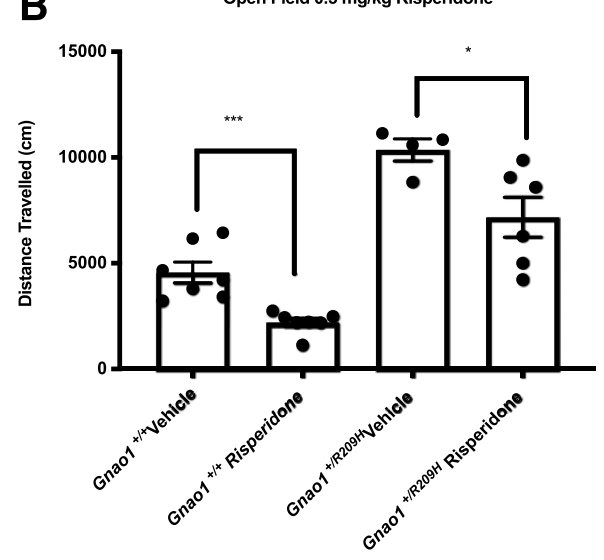

Fig. 6. Risperidone treatments decrease hyperkinetic movements in Gnao $1^{+/ R 209 H}$ (A) Gnao1 $1^{+/ R 209 H}$ mice show complete abrogation of movement compared with vehicle-treated Gnao1 $1^{+/ R 209 H}$ littermates following a $2.0 \mathrm{mg} / \mathrm{kg}$ dose of risperidone. Student's unpaired $t$ test. (B) At $0.5 \mathrm{mg} / \mathrm{kg}$, both WT and Gnao $1^{+/ R 209 H}$ exhibit a significant decrease in locomotion compared with vehicle controls. Student's unpaired $t$ test. Wild-type mice also show a decrease in locomotion after $0.5 \mathrm{mg} / \mathrm{kg}$ risperidone treatment. (C) Comparison of 2.0 and 0.5 $\mathrm{mg} / \mathrm{kg}$ treatment in WT and Gnao $1^{+/ R 209 H}$ mice. Hyperactivity of Gnao $1^{+/ R 209 H}$ mice was observed during baseline testing and recovered following the 2-day risperidone washout. $* P<0.05 ; * * P<0.01 ; * * * P<$ $0.001 ; * * * * P<0.0001$
In contrast, the G203R mutant is expressed at lower levels both in HEK cells (Feng et al., 2017) and in the mouse brain (Feng, H. Unpublished doctoral dissertation). Despite lower expression, it signals more strongly (GOF) in the HEK cell assay.

We also present two new pieces of information that provide insights into the pathogenicity of the R209H mutant $\mathrm{G} \alpha_{\mathrm{o}}$, despite its normal function in the HEK cell cAMP assay. Using a fluorescent nucleotide exchange assay with pure $\mathrm{R} 209 \mathrm{H}$ mutant $\mathrm{G} \alpha_{\mathrm{o}}$, we demonstrate that the rate of binding of the GTP analog is $\sim 6.2 \times$ faster than that of WT. This is typical for many hyperactive G protein mutants, since GDP release is the rate-limiting step for activation. Indeed, receptors enhance GDP release rates to activate the G protein (Iiri et al., 1994; Leyme et al., 2014; Toyama et al., 2017). Constitutive activation of $\mathrm{G} \alpha_{\mathrm{o}}$ by the $\mathrm{R} 209 \mathrm{H}$ mutant could lead to enhanced signaling in the indirect pathway, D2 dopamine receptor neurons in striatum. The striatum is a site of substantial $\mathrm{G} \alpha_{\mathrm{o}}$ expression, and enhanced $\mathrm{G} \alpha_{\mathrm{o}}$ signaling could contribute to the hyperactivity phenotype seen in our studies. More detailed mechanistic studies of striatal neurons will be needed to further elucidate the downstream signaling mechanisms protein (e.g., ion channels, synaptic vesicle release, or neurite outgrowth) engaged by the mutant $G_{0}$ in these mice and in patients.

Effective treatments are a key goal, as patients with the $\mathrm{R} 209 \mathrm{H}$ mutation experience repeated hospitalizations (Ananth et al., 2016; Marecos et al., 2018; Schirinzi et al., 2019). Deep brain stimulation in the internal globus pallidus has proven effective in patients with GNAO1 in attenuating the movement disorder (Kulkarni et al., 2016; Yilmaz et al., 2016; Honey et al., 2018; Koy et al., 2018). However, that invasive treatment is reserved for patients who are refractory. Risperidone is one of the oral treatments that has proven to be beneficial, specifically in a patient with the R209H mutation (Ananth et al., 2016). Risperidone is an atypical neuroleptic that antagonizes $\mathrm{D}_{2}$ and 5 -HT receptors. $\mathrm{G} \alpha_{\mathrm{o}}$ couples to myriad G protein-coupled receptors, including the dopamine $\mathrm{D}_{2}$ receptor, which is involved in movement control (Neve et al., 2004). In our study, risperidone was able to significantly decrease the hyperlocomotion seen in our Gnao1 $1^{+/ R 209 H}$ mouse model. At both the 0.5 and $2.0 \mathrm{mg} / \mathrm{kg}$ doses of risperidone, hyperactivity was attenuated in our $\mathrm{R} 209 \mathrm{H}$ mouse model. However, this response was not selective for the Gnao1 ${ }^{+/ R 209 H}$ mutant mice because the WT mice also displayed a significant decrease in locomotion. This outcome suggests that risperidone treatment may be effective in repressing global movement while not specifically targeting a Gnao1 R209H mechanism.

The new mouse model described here should provide a valuable tool for future mechanistic studies of GNAO1 encephalopathies. The fact that the mouse had very distinct behavioral changes compared with our previous Gnao1 mutant mouse models (R209H and G184S) indicates that it is very important to consider the mutant allele as well as the mutant gene in considering genetic disorders and personalized therapies.

\section{Acknowledgments}

The authors thank Dr. Michelle Mazei-Robison for her advice on organizing the behavioral battery experiments on our mutant mouse models.

\section{Authorship Contributions}

Participated in research design: Larrivee, Feng, Shaw.

Conducted experiments: Larrivee, Feng, Quinn, Shaw, Leipprandt. 
Contributed new reagents or analytic tools: Demireva, Xie.

Performed data analysis: Larrivee, Feng, Shaw.

Wrote or contributed to the writing of the manuscript: Larrivee, Feng, Demireva, Neubig.

\section{References}

Ananth AL, Robichaux-Viehoever A, Kim YM, Hanson-Kahn A, Cox R, Enns GM Strober J, Willing M, Schlaggar BL, Wu YW, et al. (2016) Clinical Course of Six Children With GNAO1 Mutations Causing a Severe and Distinctive Movement Disorder. Pediatr Neurol 59:81-84.

Arya R, Spaeth C, Gilbert DL, Leach JL, and Holland KD (2017) GNAO1-associated epileptic encephalopathy and movement disorders: c. $607 \mathrm{G}>\mathrm{A}$ variant represents a probable mutation hotspot with a distinct phenotype. Epileptic Disord 19:67-75.

Blumkin L, Lerman-Sagie T, Westenberger A, Ben-Pazi H, Zerem A, Yosovich K, and Lev D (2018) Multiple Causes of Pediatric Early Onset Chorea-Clinical and Genetic Approach. Neuropediatrics 49:246-255.

Bruun TUJ, DesRoches CL, Wilson D, Chau V, Nakagawa T, Yamasaki M, Hasegawa S, Fukao T, Marshall C, and Mercimek-Andrews S (2018) Prospective cohort study for identification of underlying genetic causes in neonatal encephalopathy using whole-exome sequencing. Genet Med 20:486-494.

Carvalho RC, Silva RH, Abílio VC, Barbosa PN, and Frussa-Filho R (2003) Antidyskinetic effects of risperidone on animal models of tardive dyskinesia in mice. Brain Res Bull 60:115-124

Danti FR, Galosi S, Romani M, Montomoli M, Carss KJ, Raymond FL, Parrini E, Bianchini C, McShane T, Dale RC, et al. (2017) GNAO1 encephalopathy: broadening the phenotype and evaluating treatment and outcome. Neurol Genet 3:e143.

Deacon RM, Nielsen S, Leung S, Rivas G, Cubitt T, Monds LA, Ezard N, Larance B, and Lintzeris N (2016) Alprazolam use and related harm among opioid substitution treatment clients - 12 months follow up after regulatory rescheduling. Int J Drug Policy 36:104-111.

Dhamija R, Mink JW, Shah BB, and Goodkin HP (2016) GNAO1-associated movement disorder. Mov Disord Clin Pract (Hoboken) 3:615-617.

Dhir A (2012) Pentylenetetrazol (PTZ) kindling model of epilepsy, Curr Protoc Neurosci Chapter 9, p Unit9.37.

Epi4K Consortium (2016) De novo mutations in SLC1A2 and CACNA1A are important causes of epileptic encephalopathies. Am J Hum Genet 99:287-298.

EuroEPINOMICS-RES Consortium; Epilepsy Phenome/Genome Project; Epi4K Consortium (2014) De novo mutations in synaptic transmission genes including DNM1 cause epileptic encephalopathies. Am J Hum Genet 95:360-370.

Feng H, Khalil S, Neubig RR, and Sidiropoulos C (2018) A mechanistic review on GNAO1-associated movement disorder. Neurobiol Dis 116:131-141.

Feng H, Larrivee CL, Demireva EY, Xie H, Leipprandt JR, and Neubig RR (2019) Mouse models of GNAO1-associated movement disorder: allele- and sex-specific differences in phenotypes. PLoS One 14:e0211066.

Feng H, Sjögren B, Karaj B, Shaw V, Gezer A, and Neubig RR (2017) Movement disorder in GNAO1 encephalopathy associated with gain-of-function mutations. Neurology 89:762-770.

Gawlinski P, Posmyk R, Gambin T, Sielicka D, Chorazy M, Nowakowska B, Jhangiani SN, Muzny DM, Bekiesinska-Figatowska M, Bal J, et al. (2016) PEHO syndrome may represent phenotypic expansion at the severe end of the early-onset encephalopathies. Pediatr Neurol 60:83-87.

Gerald B, Ramsey K, Belnap N, Szelinger S, Siniard AL, Balak C, Russell M, Richholt R, De Both M, Claasen AM, et al. (2018) Neonatal epileptic encephalopathy caused by de novo GNAO1 mutation misdiagnosed as atypical Rett syndrome: cautions in interpretation of genomic test results. Semin Pediatr Neurol 26:28-32.

Honey CM, Malhotra AK, Tarailo-Graovac M, van Karnebeek CDM, Horvath G, and Sulistyanto A (2018) GNAO1 mutation-induced pediatric dystonic storm rescue with pallidal deep brain stimulation. $J$ Child Neurol 33:413-416.

Iiri T, Herzmark P, Nakamoto JM, van Dop C, and Bourne HR (1994) Rapid GDP release from Gs alpha in patients with gain and loss of endocrine function. Nature 371:164-168.

Kehrl JM, Sahaya K, Dalton HM, Charbeneau RA, Kohut KT, Gilbert K, Pelz MC, Parent J, and Neubig RR (2014) Gain-of-function mutation in Gnao1: a murine model of epileptiform encephalopathy (EIEE17)? Mamm Genome 25:202-210.

Kelly M, Park M, Mihalek I, Rochtus A, Gramm M, Pérez-Palma E, Axeen ET, Hung CY, Olson H, Swanson L, et al.; Undiagnosed Diseases Network (2019) Spectrum of neurodevelopmental disease associated with the GNAO1 guanosine triphosphatebinding region. Epilepsia 60:406-418.

Koy A, Cirak S, Gonzalez V, Becker K, Roujeau T, Milesi C, Baleine J, Cambonie G, Boularan A, Greco F, et al. (2018) Deep brain stimulation is effective in pediatric patients with GNAO1 associated severe hyperkinesia. J Neurol Sci 391:31-39.

Kulkarni N, Tang S, Bhardwaj R, Bernes S, and Grebe TA (2016) Progressive movement disorder in brothers carrying a GNAO1 mutation responsive to deep brain stimulation. $J$ Child Neurol 31:211-214.
Law C-Y, Chang ST, Cho SY, Yau EK, Ng GS, Fong NC, and Lam CW (2015) Clinical whole-exome sequencing reveals a novel missense pathogenic variant of GNAO1 in a patient with infantile-onset epilepsy. Clin Chim Acta 451 (Pt B):292-296.

Lee E, Linder ME, and Gilman AG (1994) Expression of G-protein alpha subunits in Escherichia coli. Methods Enzymol 237:146-164.

Leyme A, Marivin A, Casler J, Nguyen LT, and Garcia-Marcos M (2014) Different biochemical properties explain why two equivalent $\mathrm{G} \alpha$ subunit mutants cause unrelated diseases. $J$ Biol Chem 289:21818-21827.

Marcé-Grau A, Dalton J, López-Pisón J, García-Jiménez MC, Monge-Galindo L, Cuenca-León E, Giraldo J, and Macaya A (2016) GNAO1 encephalopathy: further delineation of a severe neurodevelopmental syndrome affecting females. Orphanet $J$ Rare Dis 11:38.

Marecos C, Duarte S, Alonso I, Calado E, and Moreira A (2018) GNAO1: a new gene to consider on early-onset childhood dystonia. Rev Neurol 66:321-322.

McEwen DP, Gee KR, Kang HC, and Neubig RR (2002) Fluorescence approaches to study G protein mechanisms. Methods Enzymol 344:403-420.

Menke LA, Engelen M, Alders M, Odekerken VJ, Baas F, and Cobben JM (2016) Recurrent GNAO1 mutations associated with developmental delay and a movement disorder. J Child Neurol 31:1598-1601.

Nakamura K, Kodera H, Akita T, Shiina M, Kato M, Hoshino H, Terashima H, Osaka H, Nakamura S, Tohyama J, et al. (2013) De Novo mutations in GNAO1, encoding a Goo subunit of heterotrimeric $\mathrm{G}$ proteins, cause epileptic encephalopathy. Am J Hum Genet 93:496-505.

Neve KA, Seamans JK, and Trantham-Davidson H (2004) Dopamine receptor signaling. J Recept Signal Transduct Res 24:165-205.

Okumura A, Maruyama K, Shibata M, Kurahashi H, Ishii A, Numoto S, Hirose S, Kawai T, Iso M, Kataoka S, et al. (2018) A patient with a GNAO1 mutation with decreased spontaneous movements, hypotonia, and dystonic features. Brain Dev 40:926-930.

Rim JH, Kim SH, Hwang IS, Kwon SS, Kim J, Kim HW, Cho MJ, Ko A, Youn SE, Kim J, et al. (2018) Efficient strategy for the molecular diagnosis of intractable early-onset epilepsy using targeted gene sequencing. BMC Med Genomics 11:6.

Saitsu H, Fukai R, Ben-Zeev B, Sakai Y, Mimaki M, Okamoto N, Suzuki Y, Monden Y, Saito H, Tziperman B, et al. (2016) Phenotypic spectrum of GNAO1 variants: epileptic encephalopathy to involuntary movements with severe developmental delay. Eur J Hum Genet 24:129-134.

Sakamoto S, Monden Y, Fukai R, Miyake N, Saito H, Miyauchi A, Matsumoto A, Nagashima M, Osaka H, Matsumoto N, et al. (2017) A case of severe movement disorder with GNAO1 mutation responsive to topiramate. Brain Dev 39:439-443.

Schirinzi T, Garone G, Travaglini L, Vasco G, Galosi S, Rios L, Castiglioni C, Barassi C, Battaglia D, Gambardella ML, et al. (2019) Phenomenology and clinical course of movement disorder in GNAO1 variants: results from an analytical review. Parkinsonism Relat Disord 61:19-25.

Schorling DC, Dietel T, Evers C, Hinderhofer K, Korinthenberg R, Ezzo D, Bönnemann CG, and Kirschner J (2017) Expanding phenotype of de novo mutations in GNAO1: four new cases and review of literature. Neuropediatrics 48:371-377.

Seibenhener ML and Wooten MC (2015) Use of the Open Field Maze to measure locomotor and anxiety-like behavior in mice. $J$ Vis Exp e52434.

Takezawa Y, Kikuchi A, Haginoya K, Niihori T, Numata-Uematsu Y, Inui T, Yamamura-Suzuki S, Miyabayashi T, Anzai M, Suzuki-Muromoto S, et al. (2018) Genomic analysis identifies masqueraders of full-term cerebral palsy. Ann Clin Transl Neurol 5:538-551.

Talvik I, Møller RS, Vaher M, Vaher U, Larsen LH, Dahl HA, Ilves P, and Talvik T (2015) Clinical phenotype of de novo GNAO1 mutation: case report and review of literature. Child Neurology Open 2:2329048X15583717.

Tatem KS, Quinn JL, Phadke A, Yu Q, Gordish-Dressman H, and Nagaraju K (2014) Behavioral and locomotor measurements using an open field activity monitoring system for skeletal muscle diseases. J Vis Exp 51785.

Toyama Y, Kano H, Mase Y, Yokogawa M, Osawa M, and Shimada I (2017) Dynamic regulation of GDP binding to G proteins revealed by magnetic field-dependent NMR relaxation analyses. Nat Commun 8:14523.

Waak M, Mohammad SS, Coman D, Sinclair K, Copeland L, Silburn P, Coyne T, McGill J, O’Regan M, Selway R, et al. (2018) GNAO1-related movement disorder with life-threatening exacerbations: movement phenomenology and response to DBS. J Neurol Neurosurg Psychiatry 89:221-222.

Xiong J, Peng J, Duan HL, Chen C, Wang XL, Chen SM, and Yin F (2018) Recurrent convulsion and pulmonary infection complicated by psychomotor retardation in an infant. Zhongguo Dang Dai Er Ke Za Zhi 20:154-157.

Yilmaz S, Turhan T, Ceylaner S, Gökben S, Tekgul H, and Serdaroglu G (2016) Excellent response to deep brain stimulation in a young girl with GNAO1-related progressive choreoathetosis. Childs Nerv Syst 32:1567-1568.

Address correspondence to: Dr. Richard R. Neubig, Michigan State University, 1355 Bogue Street, B440 Life Science Building, East Lansing, MI 48824. E-mail: rneubig@msu.edu 